\title{
Parenting children who are enterally fed: how families go from surviving to thriving
}

\begin{abstract}
Background

Complex feeding difficulties requiring enteral (tube) feeding affect everyone around the child. Parents experience additional stress and are at risk of social isolation. This study investigated the strategies families develop and use to adjust and adapt to enteral feeding so they were not just surviving, but thriving as a family.
\end{abstract}

\section{Methods}

Twenty parents whose children had been or continued to be enterally fed were interviewed, four of them twice as their experience of enteral feeding progressed. Learning theory was used to conceptualise findings in terms of changing use of tools that mediated parents' response to feeding-related challenges.

\section{Results}

Parents encountered dilemmas relating to enteral feeding and: maintaining participation in everyday activities; managing responses to the use of tubes for feeding; and doing what feels right for their child. They used four kinds of mediating tools to overcome these: memory aids and readiness tools; metaphors and narratives; repurposed everyday objects; and personalised routines and materialities.

\section{Conclusions}

This novel account of tool use to resolve dilemmas provides an empirically and theoretically grounded basis for supporting parents to thrive despite the challenges of enteral feeding. Specifically, it can guide information given to help parents anticipate and cope with dilemmas arising from enteral feeding.

\section{Introduction: enteral (tube) feeding}

Caring for children with complex needs presents significant challenges to parents (Singhal, Baker, Bojczuk, \& Baker, 2017). However, parents often persevere as 'unsung heroes' (Carter, 2016, p. 265), developing crucial knowledge and expertise. The study investigated parents' learning as carers of children who are enterally fed.

Knowledge of the impacts enteral feeding has on families is not matched by knowledge of parents' journeys from surviving to thriving - their learning. Addressing this gap provides a fuller picture of the roles and responsibilities of parents in care of children who are enterally fed (Ramchandani, 2007) and can help healthcare professionals 'sustain and enhance parental confidence, competence and skills so that they are able to focus on being their child's parent' (Carter, 2014, p. 100).

Feeding problems affect a significant proportion of otherwise healthy children, with figures suggesting 40\% (Northstone, Emmet, Nethersole, \& ALSPAC Study Team, 2001), 45\% (Linscheid, 2006), and 50\%, rising to $80 \%$ of those with developmental delays (Borowitz \& Borowitz, 2018). For children who are malnourished or unable to eat and drink orally, enteral 
feeding (also called tube feeding) can be required to ensure growth and sustain life (Krom et al., 2019). Reasons for this include pre-term birth, airway difficulties, major surgery, cancer treatment, cerebral palsy, Autistic Spectrum Disorder, cleft palate, global developmental delay, gastro-oesophageal reflux (GOR), and congenital abnormalities (Pearce \& Duncan, 2002; Krom et al., 2019). Prevalence data for enteral feeding vary widely and are thought to be underestimated, with figures quoted between 1 and 92 per 100,000 children (Krom et al., 2019), and an international estimate suggesting 4 per 100,000 children (Edwards et al., 2016).

Enteral feeding delivers nutrition directly into the gastrointestinal system. Two common approaches include a nasogastric (NG) tube through the nose to the stomach, or a surgically placed percutaneous endoscopic gastrostomy (PEG) from the skin near the navel to the stomach (Singhal et al., 2017). Tube placement using fluoroscopic guidance is also used in interventional radiology, though is less common in Australia where this study was conducted, and had not been used with any of the participating families. Enteral feeding is required when a child cannot eat or drink orally sufficiently or at all.

While enteral feeding solves the problem of nutrition, it can be a source of difficulty. Such difficulties include bio-medical side effects on the child, but also psychosocial impacts on the family, including anxiety, emotional distress, and social isolation (Cerezo, Lobato, Pinkos, \& LeLeiko, 2011; Morton, Marion, Pappachan, \& Darlington, 2019). Once enteral feeding is established, issues relating to coping with everyday life (Enrione, Thomlinson, \& Rubin, 2005) become prominent, with elevated risk of anxiety or depression in parents (Pedersen, Parsons, \& Dewey, 2004; Pedrón-Giner, Calderón, Martínez-Costa, Borraz Gracia, \& Gómez-López, 2013). This means that in addition to nutrition and growth, enteral feeding needs to be understood and cared for with regard to child emotional well-being and social participation (Morrow, Quine \& Craig, 2007) and caregiver quality of life (Joachim et al., 2019).

A lack of information on how enteral feeding fits into everyday life is a concern (Craig, Scambler, \& Spitz, 2003; Liley \& Manthorpe, 2003; Syrmis, Frederiksen, \& Reilly, 2019). Reported difficulties include restricted ability to go out and maintain family activities, childcare problems, missing 'special time' with the child, and impinged parent-child interactions during mealtimes (Brotherton, Abbott, \& Aggett, 2007; Sleigh, 2005; Veness \& Reilly, 2008).

Mothers of children with feeding and/or swallowing difficulties describe loss and disempowerment, 'getting through the brokenness', and struggles to balance competing interests (Hewetson \& Singh, 2009, p322). Parents report stigmatization and normative expectations associated with parenting (Brotherton et al., 2007; Judson, 2004; Craig \& Scambler, 2006; Sleigh, 2005). Seemingly simple things like going to a café become complex, and household organisation is disrupted (Whiting, 2012).

Parents can become 'experts', possessing knowledge that health professionals do not (Reeves, Timmons, \& Dampier, 2006). This develops as care needs evolve over time (MacDonald \& Callery, 2007), reflecting development of skills in information process, negotiating caregiving, and adapting to changing treatments (Swallow, Lambert, Santacroce, \& Macfadyen, 2011). Despite the challenges of enteral feeding, parent narratives often convey perseverance, adaptation, and coping (Carter, 2016; Murphy, Christian, Caplin, \& Young, 2007). The learning involved is not well understood. 
Better support for families with regard to tube feeding following discharge from hospital is needed (Zamvar et al., 2014). This can be facilitated by understanding how parents learn to overcome challenges relating to enteral feeding. The study answered the following research questions:

1. What matters to parents of children who are enterally fed in their everyday practices?

2. How do parents resolve challenges associated with enteral feeding in everyday life?

In posing these questions, the study was informed by cultural-historical theory. Culturalhistorical approaches draw on the original work of Vygotsky (1997), particularly his approach to studying learning in relation to the use of 'tools' (Edwards, 2017).

Learning is understood in terms of changing ways people understand something, and changing ways they act (Edwards \& Mackenzie, 2005). Cultural-historical analysis focuses on what people do (their practices), their reasons and investments in doing so (their motive orientations), and the tools they use (Clerke et al., 2017; Hopwood, Day, \& Edwards, 2016).

A cultural-historical approach to motive focuses on what matters to oneself and others involved in a particular practice (Edwards, 2017). This study explored what mattered to parents in their everyday practices, taking into account what they felt mattered to the child who was enterally fed, siblings, and others. This was explored through Research Question 1.

Learning is conceptualised as arising as people recognise and meet demands while engaging in practices that matter to them (Hedegaard, 2018; Hopwood \& Edwards, 2017). Culturalhistorical theory directs attention to the use of tools in this process.

The tools people use in practices can take various forms. They may be physical (tape used to keep NG tubes in place, reminders placed on a fridge door), or conceptual (mnemonics, ideas, ways of categorising things) (Hopwood, 2015). The use of tools in purposeful activity is referred to as mediation. This informed analysis for Research Question 2.

Cultural-historical researchers regard mediation as significant for two reasons. First, the mediating tool redirects attention from a problem towards the solution. Second, acting in a mediated way can have a legacy: the person using the tool can be changed in the process. This is referred to as reverse action (Hopwood, 2015; Hopwood, 2019; Vygotsky \& Luria, 1994).

\section{Methods}

Data were collected by interviewing parents of children who were or had been enterally fed using an NG and/or PEG. All families were based in Sydney, Australia. They were recruited through multidisciplinary feeding clinics and word of mouth through an informal online group for parents of children who are enterally fed. The study received approval from relevant Health and University Human Research Ethics Committees (see Acknowledgements).

Twenty parents participated, two of whom were husband and wife, and two had more than one child who was enterally fed. Of the 20 children discussed, six had weaned from an NG to oral feeding, two had transitioned from an NG to a PEG and then been weaned, four were still using an NG, seven had changed from an NG to a PEG, which was still in use, and one had passed away while feeding using a PEG. The children were between several months to 7 years old, 
and reasons for enteral feeding included extreme premature birth, cleft lip/palate, developmental delay, Down syndrome, Noonan's syndrome, oral aversion linked to Autistic Spectrum Disorder, aspiration, and instances of rare genetic disorders. Seventeen children received an NG tube at or within days of birth, the remainder at 9 weeks, 35 weeks, and 14 months. The eight who fed orally transitioned away from the NG tube between four months and two years of age. Those who were fed via a PEG had this inserted between 12 and 18 months of age.

Two two-hour focus groups were conducted, follow by ten one-to-one hour-long interviews six to twelve months later. Six parents participated in a focus group only, ten participated in an interview only, and four in both. All focus groups were conducted in person. Depending on parents' preference, interviews were either conducted in person, via phone, or online videocall (six opted for phone or online interviews).

Each interview or focus group began with an invitation for parents to tell their tube-feeding story. This was informed both by input from the project's Parent Advisory Group, and on narrative interview techniques (Anderson \& Kirkpatrick, 2016). The later part of each discussion was relatively open, but guided by prompts such as: What feels easier to you now than it did initially? What advice would you give a parent who is just beginning enteral feeding? and What do you wish you had been told earlier? This approach, asking about changes in everyday practices, and how people might advise others has precedent in cultural-historical research, and avoids some of the pitfalls of asking people directly about their expertise (which can produce thinner responses). It grounds the discussion in everyday practices, which is revealing of knowledge and expertise when analysed from a cultural-historical perspective (see Hopwood \& Clerke, 2019).

Analysis iteratively combined a purposive aspect reflecting theoretical interests with grounded development of themes (Srivastava \& Hopwood, 2009). MAXQDA software was used to code the data. Two rounds of coding were conducted, each of which involved multiple iterations to identify and refine themes, and followed MacQueen, McLellan and Milstein's (1998) approach to codebook development (title, definition, inclusion/exclusion criteria, example). The first round focused on Research Question 1 and what mattered to parents. The second round identified patterns in mediating tool use in order to address Research Question 2.

\section{Results}

Table 1 outlines the main themes that were identified in relation to each Research Question. These are then considered in more detail below.

\begin{tabular}{ll}
\hline Research Question & Main analytical themes \\
\hline RQ1. What matters to parents of & 1. Maintaining participation in everyday activities \\
children who are enterally fed in & 2. Responses to the use of tubes for feeding \\
their everyday practices? & 3. Doing what feels right for the child \\
\hline RQ2. How do parents resolve & 4. Memory aids and readiness tools \\
challenges associated with & 5. Metaphors and narratives \\
enteral feeding in everyday life? & 6. Repurposed everyday objects \\
& 7. Personalised routines and materialities \\
\hline
\end{tabular}


RQ1. What matters to parents of children who are enterally fed in their everyday practices?

\section{Theme 1: Maintaining participation in everyday activities}

Parents in this study wanted a 'normal' life, which meant doing the things they would do if the child was not enterally fed. For parents of children with NG tubes, a fear of tube dislodgement hindered this. For those who could not reinsert the tube themselves, a hospital visit was required:

I was constantly watching him, worried that he's going to pull out the tube and then we've got to go back to hospital.

Activities with other children posed a risk of tube dislodgement:

He didn't have the opportunity to mingle with other kids because you're worried, they're going to pull it out. That's what they do, the first thing they do is go, "What's this?" and they lift it, and you're like:

"No!"

Focusing on what mattered to parents revealed a contradiction. Parents wanted to maintain their child's participation in everyday activities, but they also wanted to avoid tube dislodgement, hospital visits, and the associated consequences for other family members:

You're putting gloves on his hands but hang on! He wants to touch things. Little things like that, you're delaying his development... you're so focused on that tube and worried he's going to pull it out. You don't want to put him through the stress of taking him to hospital, but long-term, you're delaying him.

If both parents are focussing on that little sick kid, then the other one is left out. That's when they start to get jealous and play up.

Theme 2: Responses to the use of tubes for feeding

Parents described instances when members of the public made inappropriate comments:

Everybody stares. When you walk with the pram, somebody runs back and says, "What's wrong with your child?" I've had that.

The expectation of unpleasant encounters became a barrier to going out as parents felt they were targets of stigmatization.

Once parents realised enteral feeding would not be a quick fix, what mattered changed, from getting through a difficult but short period, to thriving despite the tube:

Early on you think this is temporary, done in a few weeks' time. Then nine months later, you're still there, so I need to work out and say, "What are we going to plan for the long term?" 
This signals the importance of tube exit planning and other strategies that clarify the expected duration of tube feeding, and the uncertainties that might surround this (Lively, McAllister, \& Doeltgen, 2019; Syrmis, Frederiksen, \& Reilly, 2019).

\section{Theme 3: Doing what feels right for the child}

The third theme concerned the importance of parents doing what they felt was right for their child. This was frequently discussed in relation to the tape used to keep an NG in place. Parents wanted to minimise the effect on the child's skin and were motivated to retain the same tape as long as possible. Each time tape was replaced risked tube dislodgement - an unpleasant experience for the child:

You want the tape to stay there at least a couple of days. It's so stressful for the baby when you're trying to rip the tape off, you're hoping they're not pulling the tube out at the same time.

Parents recognised the need for healthcare professionals to give instructions or make recommendations. However, they often found these did not fit well in their own routines and judgements. While it mattered to respect clinical opinion, it also mattered to recognise when things were not working and try something else:

I've met with the [clinical] team, and it's not working. You're going crazy. Then you think, "Let me try this" and it works. My routine, when I offer the feed - it's made a difference.

RQ2. How do parents resolve challenges associated with enteral feeding in everyday life?

This question was addressed by identifying the mediating tools parents used to overcome daily challenges. These clustered in four types, as listed in Table 1. Each is now considered in turn.

\section{Theme 4: Memory aids and readiness tools}

Memory aids and readiness tools were used to overcome barriers to getting out of the house. Enteral feeding requires considerable additional equipment to be available.

I had a bad experience, I went out and didn't have the $\mathrm{pH}$ stick, so I had to drive back.

Parents overcame this by placing checklist inside the front door, including variations for specific activities like swimming. Others pre-packed items that meant they could leave at short notice. Some had back-up supplies in handbags or in the family car. These tools helped to avoid being caught out with something crucial missing:

I had my box of supplies, my tapes, my everything. That became his box and we just replenished as we used it.

\section{Theme 5: Metaphors and narratives}

The reactions of others to enteral feeding were managed using mediating tools that were more conceptual in nature. Parents used metaphors like a 'special straw' or drew parallels with dependence on reading glasses to normalise the tube to siblings and relatives. Pre-prepared 
narratives helped parents cope with the others' scrutiny. Having these 'in mind' countered the stigma and the uncomfortable interactions that had been a barrier to going out:

Straight up, now I just say, "It's a feeding tube. That's it!" They think my child is dying. I say, "It's just for food, it's all good".

\section{Theme 6: Repurposed everyday objects}

Another group of mediating tools involved repurposed everyday objects. Household items became feeding tools and enabled participation in other activities. Cupholders were attached to prams to hold tube-feeding equipment in place, making feeding possible while going for a walk. Cheap jewellery bags were used to prevent a tube from hanging down a child's back, and make-up pads were placed over PEGs:

I had this contraption with chopsticks tied with elastic bands to keep the gravity feed up. I worked out how to attach everything to the pram, so it wasn't going to spill.

The repurposing of photographs had an important mediating function. Parents initially avoiding taking photographs of their child with the NG tube showing, but later saw photos with the tube as important and positive:

Because that's him, I want to show him his journey. It's important they know their story.

\section{Theme 7: Personalised routines and materialities}

The final set of mediating tools involved personalised routines and materialities. Parents learned to navigate hospital supply chains, sending nurses to different wards to source the tape they knew was best for their child's skin. Several learned to use the pictures printed on facial tape as a guide to cut pieces to an effective size. Common to several parents was the emergence of their own knowledge of what worked in terms of volumes and rhythms when feeding their child:

Every baby is different. How to feed, the right mixture so he doesn't vomit. I do $10 \mathrm{ml}, 5$ minutes syringe, wait 10 minutes, then another $10 \mathrm{ml}$.

\section{Discussion: thriving despite enteral feeding}

Enteral feeding is both a helpful necessity and a source of challenge (Rentinck, Ketelaar, \& Gorter, 2007). This study casts new light on parents' struggle to balance competing interests (Hewetson \& Singh, 2009).

The feeding tube was not simply a barrier to participation. It placed parents in a dilemma, forcing a choice between two opposing things that mattered. Parents were torn between motives oriented toward participation in social activities, and contrary motives to avoid negative experiences while out of the house and with others. In cultural-historical theory, conflicting motives are conceptualised as possible drivers of change.

Families took steps towards thriving through tool use that addressed these dilemmas. Particular tools re-directed their attention towards the solution. Tools of remembering and readiness 
helped avoid the risk of being caught without necessary equipment. The challenge of getting out of the house became one of using checklists, ready-packed bags, repurposed devices.

Metaphors and narratives helped parents negotiate normative expectations of parenting (Brotherton et al., 2007; Craig \& Scambler, 2006). They made the prospect of encounters with the public less daunting. Parents became experts in normalising the tube in the eyes of others, weakening the hold that others' judgements had on their everyday life, taking control back instead of feeling subject to the reactions of others (Murphy et al., 2007). This is evidence of the reverse action effect of mediation (Hopwood, 2015; Vygotsky \& Luria, 1994).

Other examples of reverse action were evident. Parents' tool use changed their relationship with the idea of enteral feeding. Photographs displaying the tube helped change enteral feeding from something to hide and resist to something that was acknowledged and even celebrated as part of a child's story. Using photographs as tools in this way had reverse action, changing parents' emotional relationship with enteral feeding.

What mattered to parents evolved, and their changing tool use both reflected these changes and drove them forward. As mediating tools helped parents with the logistics of participating in social activities, the reactions of others became important, and new tools were needed. Parents' new understandings and possibilities for action - their learning - developed together as they engaged in practices, recognising and meeting the demands that doing so presented.

\section{Conclusion}

Little is known about the knowledge parents develop as they learn and adapt to enteral feeding. Key to understanding this is recognising that what matters to parents can present conflicts, and the significance of tool use in resolving these dilemmas. This elaborates on unspoken aspects of caring (Ramchandani, 2007), offering new insights into the concrete ways in which parents adapt to and create a 'new normal' (Earle, Clarke, Eiser, \& Sheppard, 2007).

The study sample means findings are indicative rather than generalisable. Nonetheless, the theoretical approach identified patterns of tool use underpinning diverse concrete practices. These can enable those working with families of children who are enterally fed to help overcome barriers to aspects of everyday life that matter.

Specifically, this research suggests that professionals supporting parents of children who are enterally fed can make a significant and positive difference by helping them anticipate the kinds of dilemmas they may face, and by sharing some concrete strategies they might use in overcoming them. Acknowledging dilemmas of the kind highlighted in Themes 1 to 3 (everyday participation, responses to the tube, and doing what feels right) could help to legitimise parents' concerns when they arise, and help parents feel less overwhelmed. In discussing ways to overcome dilemmas and shift towards thriving, this study's findings offer particular examples that might be shared. Furthermore, the principles underpinning these (tool use focused on memory and readiness, metaphors and narratives to explain enteral feeding to others, repurposing everyday objects, and personalising routines) could be considered to explore adaptations and test out variations and alternatives attuned to particular family circumstances. Discussions with parents based on these principles could highlight ways to feel ready and prepared for going out (Theme 4), ways to explain the tube in constructive and de- 
stigmatising ways (Theme 5), find solutions in everyday objects (Theme 6) and customise habits and objects to suit their specific needs (Theme 7).

The study also makes clear the additional support and connection parents may need when caring for a child who is enterally fed. Dedicated support groups for families in such circumstances exist sporadically but are not evenly available or widely known to clinicians. The 'hot' period immediately following discharge from hospital is a time when availability of advice or support $24 / 7$ is particularly valuable, and could be offered through telehealth. Given the duration of tube feeding was so important to parents in this study, it is also suggested that tube weaning or tube exit planning should be incorporated into care, support and education for parents as early as possible, preferably around the time of tube initiation.

\section{Key messages}

- Parents of children who are enterally fed face significant challenges

- What matters to parents can create tensions between participating in 'normal' activities versus avoiding negative experiences

- Parents can resolve these dilemmas by creating and using specific tools that aid memory, readiness, normalising responses, and adapting to unique circumstances.

\section{Acknowledgements}

The authors would like to thank all the families for their participation. This research was funded by Maridulu Budyari Gumal, the Sydney Partnership for Health, Education, Research \& Enterprise (SPHERE), through the Early Life Determinants of Health Clinical Academic Group Seed Grant 2017-18 and 2018-2019.

This research was approved by the Sydney Children's Hospital Network Research Ethics Office, HREC Reference LNR/17/SCHN/340. It was also ratified by the University of Technology Sydney Human Research Ethics Committee, ID ETH17-1882.

\section{References}

Anderson, C., \& Kirkpatrick, S. (2016). Narrative interviewing. International Journal of Clinical Pharmacy, 38, 631-634. https://doi.org/10.1007/s11096-015-0222-0

Borowitz, K. C., \& Borowitz, S. M. (2018). Feeding Problems in Infants and Children: Assessment and Etiology. Pediatric Clinics of North America, 65(1), 59-72. https://doi.org/10.1016/j.pcl.2017.08.021

Brotherton, A. M., Abbott, J., \& Aggett, P. J. (2007). The impact of percutaneous endoscopic gastrostomy feeding in children; the parental perspective. Child: Care, Health \& Development, 33(5), 539-546. https://doi.org/10.1111/j.1365-2214.2007.00748.x

Carter, B. (2014). Parenting a sick child. Journal of Child Health Care, 18(2), 99-100. https://doi.org/doi:10.1177/1367493514535332

Carter, B. (2016). Perserverance and parents of children with complex health care needs: unsung heroes. Journal of Child Health Care, 20(3), 265-266. https://doi.org/10.1177/1367493516664656 
Cerezo, C. S., Lobato, D. J., Pinkos, B., \& LeLeiko, N. S. (2011). Diagnosis and treatment of pediatric feeding and swallowing disorders. ICAN: Infant, Child, \& Adolescent Nutrition, 3(6), 321-323. https://doi.org/10.1177/1941406411420141

Clerke, T., Hopwood, N., Chavasse, F., Fowler, C., Lee, S., \& Rogers, J. (2017). Using professional expertise in partnership with families: a new model of capacity-building. Journal of Child Health Care, 21(1), 74-84. https://doi.org/10.1177/1367493516686202

Craig, G. M., \& Scambler, G. (2006). Negotiating mothering against the odds: gastrostomy tube feeding, stigma, governmentality and disabled children. Social Science \& Medicine, 62(5), 1115-1125. https://doi.org/10.1016/j.socscimed.2005.07.007

Craig, G. M., Scambler, G., \& Spitz, L. (2003). Why parents of children with neurodevelopmental disabilities requiring gastrostomy feeding need more support. Developmental Medicine \& Child Neurology, 45(3), 183-188. https://doi.org/10.1111/j.1469-8749.2003.tb00928.x

Edwards, A. (2017). Revealing relational work. In A. Edwards (Ed.), Working relationally in and across practices: cultural-historical approaches to collaboration (pp. 1-21). Cambridge University Press.

Edwards, A., \& Mackenzie, L. (2005). Steps towards participation: the social support of learning trajectories. International journal of lifelong education, 24(4), 282-302. https://doi.org/10.1080/02601370500169178

Edwards, S., Davis, A. M., Bruce, A., Mousa, H., Lyman, B., Cocjin, J., Dean, K., Ernst, L., Almadhoun, O., \& Hyman, P. (2016). Caring for tube-fed children: a review of management, tube weaning, and emotional considerations. Journal of Parenteral and Enteral Nutrition \& Dietetics, 40(5), 616-622. https://doi.org/10.1177/0148607115577449

Enrione, E. B., Thomlison, B., \& Rubin, A. (2005). Medical and psychosocial experiences of family caregivers with children fed enterally at home. Journal of Parenteral and Enteral Nutrition, 29(6), 413-419. https://doi.org/10.1177/0148607105029006413

Hedegaard, M. (2018). Children's perspectives and institutional practices as keys in a wholeness approach to children's social situations of development. Learning, Culture and Social Interaction. https://doi.org/10.1016/j.lcsi.2018.04.008

Hewetson, R., \& Singh, S. (2009). The lived experience of mothers of children with chronic feeding and/or swallowing difficulties. Dysphagia, 24(3), 322-332. https://doi.org/10.1007/s00455-009-9210-7

Hopwood, N. (2015). Understanding partnership practice in primary health as pedagogic work: what can Vygotsky's theory of learning offer? Australian Journal of Primary Health, 21(1), 9-13. https://doi.org/10.1071/PY12141

Hopwood, N. (2019). Motives and demands in parenting young children: A cultural-historical account of productive entanglement in early intervention services. In A. Edwards, M. Fleer, \& L. Bøttcher (Eds.), Cultural-historical approaches to studying learning and development: Societal, institutional and personal perspectives (pp. 101-116). Springer.

Hopwood, N., \& Clerke, T. (2019). Common knowledge between mothers and children in problematic transitions: How professionals make children's motives available as a resource. In M. Hedegaard \& A. Edwards (Eds.), Supporting difficult transitions: Children, young people and their carers (pp. 91-129). Bloomsbury.

Hopwood, N., Day, C., \& Edwards, A. (2016). Partnership practice as collaborative knowledge work: overcoming common dilemmas through an augmented view of professional expertise. Journal of Children's Services, 11(2), 111-123.

https://doi.org/10.1108/JCS-08-2015-0027 
Hopwood, N., \& Edwards, A. (2017). How common knowledge is constructed and why it matters in collaboration between professionals and clients. International Journal of Educational Research, 83, 107-119. https://doi.org/10.1016/j.ijer.2017.02.007

Joachim, K. C., Farid-Kapadia, M., Butcher, N. J., Chee, A. T. A., Monsour, A., Cohen, E., Mahant, S., Guttmann, A., Offringa, M., \& Complex Care COS Consensus Meeting Group. (2019). Core outcome set for children with neurological impairment and tube feeding. Developmental Medicine \& Child Neurology. https://doi.org/10.1111/dmcn.14326

Judson, L. H. (2004). Protective care: mothering a child dependent on parenteral nutrition. Journal of Family Nursing, 10(1), 93-120. https://doi.org/10.1177/1074840703260907

Krom, H., van Zundert, S. M. C., Otten, M. G. M., van der Sluijs Veer, L., Benninga, M. A., \& Kindermann, A. (2019). Prevalence and side effects of pediatric home tube feeding. Clinical Nutrition, 38(1), 234-239. https://doi.org/10.1016/j.clnu.2018.01.027

Liley, A. J., \& Manthorpe, J. (2003). The impact of home enteral tube feeding in everyday life: a qualitative study. Health \& social care in the community, 11(5), 415-422. https://doi.org/doi:10.1046/j.1365-2524.2003.00444.x

Linscheid, T. R. (2006). Behavioral treatments for pediatric feeding disorders. Behavior Modification, 30(1), 6-23. https://doi.org/10.1177/0145445505282165

Lively, E. J., McAllister, S., \& Doeltgen, S. H. (2019). Variables impacting the time taken to wean children from enteral tube feeding to oral intake. Journal of Pediatric Gastroenterology and Nutrition, 68(6), 880-886. https://doi.org/10.1097/MPG.0000000000002330

MacDonald, H., \& Callery, P. (2008). Parenting children requiring complex care: a journey through time. Child: Care, Health \& Development, 34(2), 207-213. https://doi.org/doi:10.1111/j.1365-2214.2007.00790.x

MacQueen, K. M., McLellan, E., Kay, K., \& Milstein, B. (1998). Codebook development for team-based qualitative analysis. Field Methods, 10(2), 31-36. https://doi.org/10.1177/1525822x980100020301

Morrow, A. M., Quine, S., \& Craig, J. C. (2007). Health professionals' perceptions of feeding-related quality of life in children with quadriplegic cerebral palsy. Child: Care, Health \& Development, 33(5), 529-538. https://doi.org/10.1111/j.13652214.2006.00709.x

Morton, K., Marino, L. V., Pappachan, J. V., \& Darlington, A. S. (2019). Feeding difficulties in young paediatric intensive care survivors: A scoping review. Clinical Nutrition ESPEN, 30, 1-9. https://doi.org/10.1016/j.clnesp.2019.01.013

Murphy, N. A., Christian, B., Caplin, D. A., \& Young, P. C. (2007). The health of caregivers for children with disabilities: caregiver perspectives [Article]. Child: Care, Health \& Development, 33(2), 180-187. https://doi.org/10.1111/j.1365-2214.2006.00644.x

Northstone, K., Emmet, P., Nethersole, F., \& ALSPAC Study Team. (2001). The effect of age of introduction to lumpy solids on foods eaten and reported feeding difficulties at 6 and 15 months. Journal of Human Nutrition and Dietetics, 14(1), 43-54. https://doi.org/10.1046/j.1365-277x.2001.00264.x

Pearce, C. B., \& Duncan, H. D. (2002). Enteral feeding. Nasogastric, nasojejunal, percutaneous endoscopic gastrostomy, or jejunostomy: Its indications and limitations. Postgraduate Medical Journal, 78, 198-204. https://doi.org/10.1136/pmj.78.918.198

Pedersen, S. D., Parsons, H. G., \& Dewey, D. (2004). Stress levels experienced by the parents of enterally fed children. Child: Care, Health \& Development, 30(5), 507513. https://doi.org/10.1111/j.1365-2214.2004.00437.x 
Pedrón-Giner, C., Calderón, C., Martínez-Costa, C., Borraz Gracia, S., \& Gómez-López, L. (2013). Factors predicting distress among parents/caregivers of children with neurological disease and home enteral nutrition. Child: Care, Health \& Development, 40(3), 389-397. https://doi.org/10.1111/cch.12038

Ramchandani, P. (2007). What are parents for? Child: Care, Health \& Development, 32(2), 115-116. https://doi.org/10.1111/j.1365-2214.2007.00736.x

Reeves, E., Timmons, S., \& Dampier, S. (2006). Parents' experiences of negotiating care for their technology-dependent child. Journal of Child Health Care, 10(3), 228-239. https://doi.org/10.1177/1367493506066483

Rentinck, I., Ketelaar, M., Jongmans, M., \& Gorter, J. (2007). Parents of children with cerebral palsy: A review of factors related to the process of adaptation. Child: Care, Health \& Development, 33(2), 161-169. https://doi.org/10.1111/j.13652214.2006.00643.X

Singhal, S., Baker, S., Bojczuk, G., \& Baker, R. (2017). Tube feeding in children. Pediatics in Review, 38(1), 23-34. https://doi.org/10.1542/pir.2016-0096

Sleigh, G. (2005). Mothers' voice: a qualitative study on feeding children with cerebral palsy. Child: Care, Health \& Development, 31(4), 373-383. https://doi.org/10.1111/j.13652214.2005.00521.x

Srivastava, P., \& Hopwood, N. (2009). A practical iterative framework for qualitative data analysis. International Journal of Qualitative Methods, 8(1), 76-84. https://doi.org/10.1177/160940690900800107

Swallow, V., Lambert, H., Santacroce, S., \& Macfadyen, A. (2011). Fathers and mothers developing skills in managing children's long-term medical conditions: how do their qualitative accounts compare? Child: Care, Health \& Development, 37(4), 512-523. https://doi.org/10.1111/j.1365-2214.2011.01219.x

Syrmis, M., Frederiksen, N., \& Reilly, C. (2019). Characterisation of information hospitals provide parents on tube feeding, including tube weaning. Journal of Pediatric Nursing, 44, e91-e97. https://doi.org/10.1016/j.pedn.2018.11.008

Veness, C., \& Reilly, S. (2008). Mealtime interaction patterns between young children with cerebral palsy and their mothers: characteristics and relationship to feeding impairment. Child: Care, Health \& Development, 34(6), 815-824. https://doi.org/10.1111/j.1365-2214.2008.00846.x

Vygotsky, L. S. (1997). The collected works (Vol. 4): the history of the development of the higher mental functions. Plenum Press.

Vygotsky, L. S., \& Luria, A. R. (1994). Tool and symbol in child development. In R. van der Veer \& J. Valsiner (Eds.), The Vygotsky reader (Vol. 99-174). Blackwell.

Whiting, M. (2012, Mar). Impact, meaning and need for help and support: The experience of parents caring for children with disabilities, life-limiting/life-threatening illness or technology dependence. Journal of Child Health Care, 17(1), 92-108. https://doi.org/10.1177/1367493512447089

Zamvar, V., Puntis, J., Gupte, G., Lazonby, G., Holden, C., Sexton, E., Bunford, C., Protheroe, S., \& Beath, S. (2014). Social circumstances and medical complications in children with intestinal failure. Archives of Disease in Childhood, 99(4), 336-341. https://doi.org/10.1136/archdischild-2013-304482 